Article

\title{
Work-Life Balance, Organizations and Social Sustainability: Analyzing Female Telework in Spain
}

\author{
Ana Gálvez ${ }^{1}\left(\mathbb{D}\right.$, Francisco Tirado ${ }^{2, *(\mathbb{C})}$ and M. Jesús Martínez ${ }^{3}$ \\ 1 Faculty of Psychology and Education Sciences, Universitat Oberta de Catalunya, 08018 Barcelona, Spain; \\ agalvez@uoc.edu \\ 2 Department of Social Psychology, Universitat Autònoma de Barcelona, 08193 Bellaterra, Spain \\ 3 Faculty of Economics and Business, Universitat Oberta de Catalunya, 08035 Barcelona, Spain; \\ mmartinezarg@uoc.edu \\ * Correspondence: Franciscojavier.tirado@uab.es
}

Received: 30 January 2020; Accepted: 24 April 2020; Published: 27 April 2020

check for updates

\begin{abstract}
The concept of work-life balance has recently established itself as a key component on route maps drawn up in the pursuit of social sustainability, both on a local scale, represented by individual organizations, and on a more general one, represented by global institutions such as the United Nations. Our article analyzes telework's use as a political tool within organizations that either boost or hinder the development of social sustainability. Additionally, we propose the notion of "life sustainability" to analyze how female teleworkers describe the link between specific work cultures and the possibility of fulfilling social sustainability goals in local work environments through the achievement of a good work-life balance. Our research was performed following a qualitative approach, drawing from a sample of 24 individual interviews and 10 focus groups with a total of 48 participants, all of which are female teleworkers with family responsibilities. Our main findings allow us to summarize the interviewees' social perceptions into two categories, which we have dubbed 'life sustainability ecologies' and 'presence-based ecologies'. We conclude by discussing female teleworkers' claim that work-life balance is directly linked to social sustainability and that the latter goal will remain out of reach as long as the issue of balance goes unresolved.
\end{abstract}

Keywords: social sustainability; work-life balance; female teleworkers; organizational culture; life sustainability ecologies; qualitative methods

\section{Introduction}

In 2015, the United Nations established 17 sustainable development goals (SDGs) for the entire planet to work towards and attain by 2030 [1], an initiative supposedly entailing a binding contract for all countries forming part of the organization. Three of the SDGs directly target branches of science with ties to organizational studies (SDG 8: decent work and economic growth; SDG 9: industry, innovation and infrastructure; and SDG 12: responsible consumption and production). It is explicitly stated that these goals will come as an enormous challenge for organizations and will have a significant impact on them in terms of management [2-4]. Likewise, there are at least three other SDGs that prove relevant in this regard (SDG 5: gender equality; SDG 10: reduced inequalities; and SDG 11: sustainable cities and communities). The fact that at least six of the seventeen SDGs established by the United Nations target organizations reflects the crucial role they play in creating a sustainable world and, at the same time, their importance in reducing inequality, with the ultimate goal of ensuring permanent sustainability $[5,6]$.

In this regard, the last decade has seen proposals advocating processes of change in organizations to enhance their commitment to: (a) their surrounding environment; (b) the community in which 
they carry out their activities; (c) the efficient and clean use of energy; and (d) production and work organization procedures that ensure workers' future well-being and reduce social and economic inequalities [7-10]. Such proposals often overlook the importance of guaranteeing a work-life balance. Oddly enough, this absence is not reflected in the theories posited in academic literature. In fact, there is broad consensus on the fact that work-life balance is of vital importance in industrialized nations and that it is becoming a pressing issue in developing countries as well. In the former case, the massive incorporation of women into the workplace, the rise in the number of single-parent families, and the increase in dependency as a result of ageing populations are some of the factors that explain why the issue of work-life balance has become a key item on the agendas of a number of European Union states [11-18]. In the latter, the sudden creation of companies in areas of Africa and Asia as the result of outsourcing (with the consequent implementation of long working hours), the pace of transformation of local communities and unforeseen changes in age-old family traditions make this balance a new and urgent problem $[19,20]$.

Reflecting the conclusion of academic literature, recent years have witnessed examples of companies, organizations and institutions that have introduced meaningful changes in their development agendas to ensure and promote a proper work-life balance. What is interesting about these examples is that the transformations they propose are regarded as strategic and crucial in guaranteeing the very survival of the companies in question, increasing their ability to attract and retain talent, boosting productivity and, in short, sharpening their competitive edge [21-23]. The majority of these transformations involve promoting flexibility in the organization of working time, maternity leave, the right to special childcare-related vacation time and telework. This last item is especially important, as working from home has appeared in the world of organization as a great solution to the problems hindering a proper work-life balance. In this regard, the resolution adopted by the European Parliament and the Council on measures for achieving a work-life balance recommended flexible working models, including teleworking.

Telework has been analyzed from a wide variety of viewpoints, receiving both great support and harsh criticism. Supporters underline telework's great potential to harmonize the different facets of people's lives, permitting space and time management that proves beneficial to workers [24-27], while also cutting costs for organizations [28-30]. However, other authors reveal its more controversial and negative ramifications [31-34]. Their perspective highlights the pernicious impact of teleworking, portraying teleworkers as being overloaded with work as they directly and intensely experience the conflicts and hurdles that arise when salaried, family, domestic and personal work coexist $[11,35]$. It also points to how, in the case of women, teleworking can bolster the role they are traditionally saddled with as those chiefly responsible for family-related matters [36-39].

Nevertheless, teleworking has not, to date, been examined as a tool that can be used for political denunciation or for proposing organizational transformations that target the seventeen sustainable development and social sustainability goals set by the United Nations. This, it is that this article will examine this very issue. Leveraging work carried out over the course of a number of years with female teleworkers, we will show that they resort to this form of working to point out two extremely important issues. Firstly, they explain which organizational conditions help make teleworking a success or a failure. Secondly, they indicate that difficulties in successfully teleworking and, therefore, in attaining a proper work-life balance, go far beyond technical issues impeding a fit between the rhythms of everyday life and work. Work-life balance appears as one more goal for helping organizations to become sustainable. In other words, it is an important element that must strongly feature on any social sustainability route map, both on a local scale, represented by individual organizations, and on a more general one, represented by global institutions such as the United Nations, with the role of safeguarding human rights. Therefore, our article contributes to the study of the relationship between organizations and the problem of social sustainability by: (a) showing how telework is employed by users as a political tool for denouncing unfavorable employment situations; (b) indicating telework's association with organizations that boost or hinder the development of social sustainability in the field 
of work; and (c) proposing the notion of 'life sustainability' to analyze how female teleworker describe the link between specific work cultures and the possibility of fulfilling social sustainability goals in local work environments though the achievement of a work-life balance.

As is often the case in qualitative research, our proposals do not adhere to one single theory or set of works. Rather, they are based on two different kinds of academic contributions. First, we find critical and qualitative research providing a number of insights into the perception and experiences that (male and female) employees have of the relationship between their overall quality of life and their work, family and personal activities [40,41]. Additionally, this tradition has established an active and urgent agenda [14,42] to answer the following questions: (a) What practices, cues and rituals do home-based teleworkers rely on to smooth the transition between their home and work roles [43,44]?; (b) How does technology change workers' concept and use of time and space [45,46]?; (c) What paradoxes and dilemmas are created by the discourse surrounding home-based teleworkers and their flexibility [47-49]?; and (d) What binds the relationship between flexibility, telework and identity [41]? Our research takes up the baton in this line of interest and widens its scope by exploring an entirely new topic: the relationship between female telework and social sustainability.

Second, our work sticks to a conceptual framework called "New Urban Studies" [50-52]. This defends the idea that social sustainability is a term overlapping with others such as solidarity, cohesion, integration, etc. In this vein, an umbrella concept encompassing factors including education, mental and physical health, poverty, social equity or participation is also considered. However, studies like these put forward that research grappling with social sustainability tends to forget that this cannot be analyzed in isolation without considering environmental and economic sustainability. In the bind between social and economic sustainability, New Urban Studies establishes a new theoretical and practical challenge associated with achieving greater social sustainability: the impact teleworking has on it [52]. The Urban Studies framework points out several lines of research to clarify this relationship: (a) establishing how relevant for social sustainability working without commuting between home and work is; (b) analyzing what kind of transformations telework triggers in local and international organizations to align them with the objectives of social sustainability; (c) examining how telework could change our cities and turn them into a more sustainable habitat; (d) understanding how telework producing little transformations in local practices inside organizations can trigger effects on a global scale and contribute to strengthening social sustainability objectives.

As noted above, our research focuses on female Spanish teleworkers and analyzes how this form of work affects, in practice, their work-life balance. The article's second section addresses the vital relationship between work-life balance and social sustainability, completing its analysis with an in-depth look at the importance of teleworking in the knowledge economy, as well as its potential to help redress the issues hindering work -life balance. In the third section, we provide the details of our research methodology. There are two reasons why our sample included only women. The first is that a great deal of literature shows that the issue of work-life balance is gendered $[14,19,53-56]$ and that gender differences remain embedded in the ways in which respondents negotiate their home and work lives [15,57-59]. Therefore, we believe that women experience the greatest number of problems in achieving a proper work-life balance. The second reason is associated with the fact that women with domestic care burdens are those who most commonly take advantage of this form of work and other work flexibility measures $[15,60,61]$. In the fourth section, we present the results of our research; namely, two types of discourse that summarize the social perception of our interviewees, which we have dubbed 'life sustainability ecologies' and 'presence-based ecologies'. We conclude by discussing how organizations' intention to support work-life balance must be accompanied by their understanding of this balance as a key component of social sustainability, entailing: (a) an improvement in workers' working conditions; (b) greater integration of organizations in the community; (c) a direct commitment to combatting gender differences and promoting equality; and (d) an undertaking to ensure the future of the community and the organization, given that it respects the care and upbringing of dependent persons such as children. 
In this vein, our paper contributes to three specific areas of research. Firstly, our own research reflects a line of work that is currently being explored by a number of fields in the organizational world: the analysis of female teleworkers' social perception of their way of working and the relationship it establishes with their work-life balance. Secondly, it shows how telework can become a political tool for denouncing situations of inequality. Lastly, it makes progress in highlighting female teleworkers' claim that work-life balance is directly linked to social sustainability and that the latter goal will remain out of reach as long as the issue of balance goes unresolved.

\section{Literature Review and Conceptual Framework}

\subsection{Wor-Life Balance and Social Sustainability}

As pointed out by Rao [23], the drawing up of an agenda for sustainable human development, like that of the United Nations, will not be complete until the issue of work-life balance is approached as a general problem that affects human rights. Work-life balance as an issue firstly relates to personal dignity in the work environment, but it also represents an in-depth approach to gender equality, community development and a future in which children's care and upbringing is not the sole responsibility of their parents. Therefore, work-life balance should be viewed as more than just a way to coordinate work and family time and space. Rather, it should be regarded as an issue that directly impacts on how we organize our societies to make them fairer and more human [62] and as one of the core themes of so-called 'social sustainability'.

This is a notion to which growing importance has been attached in academic literature over the course of the last decade. Its origins are found in the concept of sustainable development [63], the term being coined to emphasize the strong relationship between the sustainable environmental development of human beings and the labor-related and cultural facets involved in their everyday lives. So, while the notion of sustainable development focuses on the relationship between human life and its environmental impact, that of social sustainability reminds us that said lives cannot be analyzed without taking into account cultural dimensions such as those entailed by concepts like 'capitalism', 'work', 'community', etc. [64]. From the standpoint of social sustainability, no real, effective progress can be made in the field of human sustainability without ensuring the involvement of players such as organizations and businesses or without their acceptance of the fact that their agendas for community engagement must include, at the top of the list, the issue of work-life balance.

These are the lines already pointed to by the contributions of other research. For example, Rao [23] suggests that, if we create a culture that truly supports work-life balance, it is also likely to promote sustainable human development though greater role-related engagement of individuals and groupings such as organizations and institutions. Similarly, Di Fabio [9] dares to go a little further and refers to healthy organizations as those whose business structures contemplate work-life balance as a basic component of individual well-being and, therefore, of a more sustainable society. White and Thatcher [65], Mushfiqur et al. [66] and Haar et al. [62] provide good examples of specific research that analyzes work-life balance's direct impact on social sustainability. The first examines the potential role of specific work-related technologies like mobile phones in this balance; the second, a range of work-life balance measures that improved the sustainability of a specific community (Nigerian female medical doctors); and the third, the leading role that work-life balance plays in achieving the SDGs. In a similar way, Kobayashi, Eweye and Tappin [67] have analyzed how managers in a range of Japanese companies tackle and react to the work-life balance phenomenon and its relationship with sustainability.

Another research line [68-70] shows that, while certain governments and international institutions back and promote important work-life balance measures, organizational structures and cultures do not always welcome them with the required engagement. Often times, they may even employ logic that helps to ensure that women continue to bear the brunt of the problems brought on by a work-life balance and, accordingly, prevents men from becoming engaged in them [53,54]. The most 
commonplace of these are: (a) a workplace organization that rewards staying at one's desk for long working hours; (b) biased perceptions regarding the capacities and responsibilities of each gender with regard to caring for the family; and (c) business environments that value markedly masculine abilities [71-74]. Such logics lead to organizational cultures setting professional careers above caring for the family. They do not, therefore, foster a work-life balance and ultimately become labor, social and economic structures that are to the detriment of social sustainability.

Thus, as a number of authors have shown that an organization's culture can be a hindrance to resolving the work-life balance issue and create a clear gap between the work experience of men and women, exacerbating the reproduction of social inequalities [37,55,56,75-77]. In such cultures, physical presence and a commitment to one's job are key factors in determining the success of one's career. By way of contrast, a concern for work-life balance and family care is seen as an obstacle to workers' professional development and their productivity within an organization. The direct result is a work climate in which women are discriminated against, as they are faced with the dilemma of having to choose between their professional careers and their work-life balance $[18,69,78,79]$. This is why, for a decade now, some authors have been arguing that organizations need to transform their cultural matrices: in other words, the set of norms that define commitment to one's job, success at work and proper behavior with regard to family commitments [3,80-82]. Nevertheless, as pointed out by a significant part of the literature on the relationship between sustainability and organizational change $[83,84]$, the emphasis placed by organizations in their search for a culture of sustainability focuses on issues associated with the environment, energy efficiency and their direct impact upon the surrounding community, all too often overlooking the importance of the work-life balance dimension.

\subsection{The Knowledge Economy, Teleworking and Work-Life Balance}

The cultural, economic and labor reality encapsulated in the concept of social sustainability has been characterized as the 'knowledge economy', the 'new economy', the 'digital economy' or the 'network economy'. It represents a significant realignment, in which the consumption of material goods gradually gives way to a prevalence of knowledge and information. As a result, our everyday lives become structured on the basis of intangible resources, knowledge and information technologies. It is thus argued that the opportunities for the development of countries, corporations, organizations and individuals are influenced by techno-scientific advances, knowledge generation and information management $[85,86]$. Within such a context, telework appears as the star form of working that, among other things, helps solve the seemingly never-ending issue of work-life balance.

Telework first appeared in the 1970s as a new form of labor organization that could provide a solution to many individual, social and organizational problems. It was claimed that it could cut traffic in cities and, therefore, pollution and our dependence on fossil fuels, as well as open up a new arena of employment opportunities for those with difficulties accessing the normal labor market. Similarly, a reduction in employment costs was forecast, as was an increase in productivity and, of course, a social revolution. Its implementation would solve in one stroke the work-life balance problem, increasing job satisfaction and employees' engagement with their organizations' goals [87-91].

Although teleworking is a complex phenomenon that depends upon variables such as contract type, status within an organization, the work's location and the type of task being performed, there is broad consensus in literature when it comes to its definition. It is defined as an employment practice that is decentralized -in other words, undertaken outside of an organization's place of operation-and which depends upon the use of information and communication technologies [92-94].

After a number of decades of implementation and development, a wide range of studies have assessed the real impact teleworking has on our organizations and, particularly, on our everyday lives. For example, there has been a broad examination of how teleworking cuts the cost of investment in infrastructure, equipment, electricity and water [95]. It has also been seen to lead to an increase in productivity and a reduction in absenteeism $[92,96]$. Nevertheless, other studies point out that telework may also give rise to risks similar to those affecting the self-employed, such as worsening contractual 
conditions and legal cover for workers [97,98]. Similarly, the implications associated with the social sustainability of telework have been analyzed, and the conclusions do not seem to reach any definitive agreement. While some studies state that it may enhance social sustainability in terms of human resources management and cutting traffic [24,99-101], others reach the exact opposite conclusion [102].

In the last decade, this type of study has undergone an interesting twist. Instead of focusing on telework as a device that fosters certain practices and limits others, researchers have resorted to qualitative methodologies to study the opinions, perceptions, discourses and cultural values of teleworkers with regard to their form of working [103,104]. Our article is framed within this new research perspective. Our qualitative approach allowed us to look at the social perception of female Spanish teleworkers with regard to their form of working. In our research, we encountered two interrelated dimensions that had not yet been subject to much analysis in academic literature. The first is associated with how female teleworkers describe the conditions an organization must implement to help ensure that teleworking is successful in achieving a work-life balance. The second, closely connected to the first, shows that our interviewees refer to telework as something that is much more than a mere work activity tool. They refer to it as a logical framework-one that is directly associated with social sustainability-which allows them to denounce the political climate that dominates in many Spanish organizations. Via telework, interviewees reject the systems preventing them from having a successful professional career and caring for their family at the same time, thereby calling out against organizations which keep the community in which they carry out their activities from functioning properly.

\section{Methodology}

\subsection{Data Collection}

Our research was performed following a qualitative approach, drawing from a sample of 24 individual interviews and 10 focus groups, each of which comprised from 4 to 6 participants, totaling 48 in all. Thus, 72 female teleworkers-all with family responsibilities-partook in either an individual interview or a focus group. Broken down by professional category, 8 of the participants were senior-level personnel, 22 were intermediate-level personnel, 7 were university lecturers, 25 were technicians, 6 were administrative secretaries, and 4 were translators. A total of $20 \%$ of the women in the study were full-time teleworkers, with the remaining $80 \%$ carrying out telework from between one afternoon to three days per week. The sample was drawn up to provide a faithful reflection of the employment situation in Spain. Accordingly, the distribution of the 72 teleworkers based on the type of organization in which they worked was as follows: $22.2 \%$ were from private companies, $20.8 \%$ from state-owned companies, $36.1 \%$ from private universities, $4.2 \%$ from state universities, and $16.7 \%$ were self-employed and working for several companies at once.

Given their high level of representation, it is important to note that 20 different organizations or companies took part in the study (not including the aforementioned self-employed workers). In all, $60 \%$ of these organizations were large companies (with over 500 employees), $20 \%$ were medium-sized companies (with between 50 and 500 employees), and the final 20\% were small companies (with fewer than 50 employees). In preparing the sample, we sought a variety of organization types and differences in participants' professional category, their weekly time spent teleworking and their family situation. To build the sample based on these criteria, a snowball sampling method was used [105]. To commence this snowball, we contacted individuals in different companies with telework programs and sent emails and different alerts to colleagues who might know others who teleworked. Potential participants were contacted by telephone and reviewed to ascertain whether they fit the selection criteria mentioned above. All interviews and focus groups were recorded after the signing of an informed consent release. The individual interviews lasted from 45 to $60 \mathrm{~min}$, and the focus group sessions, from $2 \mathrm{~h}$ to $2 \mathrm{~h}$ and $30 \mathrm{~min}$. The interviews were carried out in Spanish, in cities such as Alicante, Barcelona, Bilbao, and Madrid, Spain. The focus group sessions were carried out in closed spaces (meeting rooms, offices, 
etc.) in the organizations in which participants worked, while individual interviews took place in their homes. The following tables (Tables 1-3) summarize the sample distribution.

Table 1. Telework status, expressed as a percentage.

\begin{tabular}{cc}
\hline Percentage & Telework Status \\
\hline $20 \%$ & Full-time teleworkers \\
$80 \%$ & Part-time teleworkers (carrying out telework from between one afternoon and three days per week) \\
\hline
\end{tabular}

Table 2. Organizations participating in the sample, distribution by percentage.

\begin{tabular}{cc}
\hline Organization & Distribution \\
\hline Private companies & $22.2 \%$ \\
State-owned companies & $20.8 \%$ \\
Private universities & $36.1 \%$ \\
State universities & $4.2 \%$ \\
Self-employed workers & $16.7 \%$ \\
\hline
\end{tabular}

Research was performed using two different interview guides. One was prepared especially for individual interviews and covered the following topics: (a) motivations for choosing telework; (b) the pros and cons of teleworking; (c) the relationship between telework and everyday home life; (d) the impact of the job on their domestic organization; (e) opinions on gender differences in the teleworking-work/life balance relationship; (f) telework and professional career; and (g) acceptance of telework in the workplace. The second was aimed at focus groups and was structured around the following issues: (a) the effectiveness of telework in achieving a work-life balance; (b) the relationship between gender and telework; (c) telework and space and time reorganization in the home; (d) the pros and cons of telework for the organizations using it; and (e) gender differences and telework. These guides were designed to offer a flexible framework that could be adapted according to participants' responses by adding new questions and themes on the fly [105].

\subsection{Data Analysis}

As noted above, consent was given by the participants to record and transcribe the interviews and focus groups. From the transcripts, fragments were extracted, called 'verbatims'. These fragments consisted of opinions or assertions that are particularly relevant in responding to or clarifying one of the issues raised in the interview guide. The verbatims were analyzed for their thematic content, taking place in three phases: pre-analysis, codification, and categorization. In the first stage, our aim was (a) familiarization with the data as a whole; (b) organization of information for analysis; and (c) identification of relevant content in line with the research objectives. In the second stage, we divided up the interviews according to our findings in the first stage. We established a context unit for every relevant piece of content in order to properly understand and interpret it. Then we catalogued the analysis units according to the following criteria: (a) meaning; (b) frequency of appearance; and (c) evaluation by the interviewee. In the final stage, we organized and classified the analysis units into categories. Qualitative content analysis was carried out using the ATLAS.ti program.

\section{Results: Life Sustainability Ecologies vs. Presence-Based Ecologies}

Our results are opinions, which we show using what are called 'verbatims' in qualitative perspectives. These relevant fragments spoken by our interviewees have been selected due to their value in illustrating an important topic in the research. The set of all verbatims shed light on our interviewees' social perception of the relationship between telework and work-life balance. Their opinions, and the verbatims representing them, have been grouped into three different dimensions. We view the dimensions as types of discourse because they revolve around specific topics, highlight 
the coherence and logic used, and present a set of issues on which this general logic is built. The three dimensions are:

(a) The assessment of how organizations implement, promote and deploy telework;

(b) The everyday use of this form of working and its integration into one's home life; and

(c) The effects of telework on one's everyday life and professional career.

In presenting the results, the dimensions are given the following names:

Axis 1: the implementation of telework

Axis 2: integration into domestic and family life

Axis 3: the effects of telework

In turn, the opinions expressed in these three axes make up two large-scale categories of social perception, which we have named 'life sustainability ecologies' and 'presence-based ecologies'. In what follows, we will provide a detailed description of these two categories and, for each one, present certain verbatims spoken by our participants to illustrate their opinions with respect to the three axes.

There are two reasons behind our decision to name the two categories as we have done. The first is that our interviewees directly described their organizations as having one of these two viewpoints. They pointed out that some companies lay the groundwork for life sustainability-a philosophy similar to social sustainability-and that in work environments such as these it is easy and simple to find a harmonic work-life balance. Meanwhile, in other companies, priority is given to a more classical presence-based logic, in which finding such a balance proves impossible. The second reason is associated with the word 'ecology', which prevails in our research over other, more commonplace terms, such as 'culture' or 'system'. This is because our participants' explanations of their experiences included references to their organizations as a whole or as an environment in which they were positioned, with this positioning working as either a catalyst for certain actions or a disrupter of or hindrance to others. As some authors [106] point out, the notion of 'ecology' goes beyond that of 'culture', focusing on aspects such as meanings, rituals and signals in referring to a whole that delimits a set of social relationships and the meanings attached to them. Additionally, it goes beyond that of a 'system' in that it stresses ecological perspectives' focus on a subject within a particular context which, in turn, establishes the subject's behavior by means of intrapersonal, interpersonal, institutional, community and public policy-related factors $[107,108]$.

\subsection{First Category: Life Sustainability Ecologies}

The three discourse axes mentioned above are expressed in this social perception category as follows:

\subsubsection{Axis 1: The Implementation of Telework}

The first of our axes is associated with the manner in which telework is implemented within an organization. The first issue to clearly appear in our interviews is related to the technological support required for this form of working. Our interviewees stated that their organizations make the technological equipment required to successfully carry out teleworking available to their workers.

... the facilities ... with ADSL, er ... and a VPN, a ... secure line, and I'm working at home, or anywhere, a hotel, or even an internet café, with my computer, with a private line and at a reasonable speed, and ... it's like I was here at the office. So, there, also, well ... well the telephone connection you can make ... er ... with some numbers in Spain that are toll-free, shall we say, so that you can call anywhere (...) And so I'm connected like I would be here [ ... ], in this sense they have it well sorted, because, er, there are measures, well, programs for flexibility and teleworking is one of them, and, well, it suits me and I take advantage of it ... (I017_manager_part-time teleworking) 
The second issue detected relates to whether the organization has explicit work-life balance programs or offers flexible working measures, in which telework is a real possibility that staff whose duties so permit can take advantage of.

But I ... what I'm referring to, and in this I agree with you, however, there must be a regulatory framework, put it that way, which ... which allows all teleworkers to in some way benefit either from teleworking or from a work-life balance, and that, on this basis, obviously, everyone is responsible for their work, because obviously ... the fact of introducing telework implies the organization trusts people, right? (FG3_005_training manager_part-time teleworking)

A third issue relates to the support openly expressed by senior management and non-teleworking staff, both of whom regard teleworking measures as positive and show great respect for each worker's family situation.

... well, here everyone's got something, in my case I do it for the kids, but I have women coworkers who have really elderly parents and, well, everyone ... has something going on, and in that regard the organization shows respect, they don't ask that of us ... if you have young children ... but it's taken for granted that everyone has their needs. (FG9_060_assistant manager_full-time teleworking)

Support from senior management is a key factor in ensuring that telework operates properly. The most frequently mentioned aspect associated with this is the peace of mind that they will not be penalized simply for not being physically present in the organization. Directly related to this support are organizations' methods for planning work based on clear, explicit goals.

It needs to be assessed. A results-based assessment, with the establishment of carefully calculated goals, on a monthly basis, systems for this assessment in a year ... in a year, goals cannot be assessed, as nobody has a year's long-term memory. Goals need to be ... shorter in timescale for labor relations much more thought out and then, see how telework, well regulated and well done, so, it fits in all of this. In the company's own entire work organization, right? (FG3_005_training manager_part-time teleworking)

Sometimes, our interviewees stated that the subject of goal-based planning gives way to a kind of cultural or value-based metaorganization.

What we do ... this is a ... this is very important: company XXX, as a company, fosters values-based management, OK? Let's say, I don't know if you've spoken to other companies, but until a few years ago it was results-based ... we go a bit further and do it by values, in other words: "The company has some cultural values that also entail business results", I mean, they're included, that's key, and what really ... what we do, we've ... we have, we set some personal goals, they're called ... personal ... $B C$... personal business commitments ... oof! (laughs), this is a personal commitment, in other words ... I ... yep, from top to bottom ... They are documented and continuously monitored, in other words ... and the same goes for me and my staff. I have my business goal, which everyone is aware of, and the goals, not so much business ones, but of personal development, aligned with the company's values, OK? (I031_business unit manager_part-time teleworking)

\subsubsection{Axis 2: Integration into Domestic and Family Life}

For this second axis, we looked at the integration between telework and these women workers' daily lives. Here, telework appears linked to the possibility of self-managing one's time and that this means being able to autonomously arrange the different aspects of one's everyday life. In life sustainability ecologies, such arrangements are presented as fluid and harmonious. The most noted example is the ability to manage and carry out different daily tasks and handle various responsibilities in accordance with one's individual needs, as they appear as pieces of a puzzle that have to be fit together throughout the course of the day. 
Time is what's most important, it's all, I dunno. From the silliest thing that in another job would be a disaster, like your washing machine breaks down and they come to fix it, it's crucial, you're working and the technician comes and repairs it. In another company you'd have to arrange ... well, it'd be a nightmare. These might seem like small things, but they're really important. (I040_social media specialist_part-time teleworking)

The feeling of independence and the appearance of a strong sense of controlling one's life in and out of work were key factors for many interviewees, as clearly reflected in the following verbatim:

The way I am, the key advantage of teleworking is that it gives me the flexibility to organize my many roles as mother (... ), studying, and so on ... if not, it would be impossible. And, for me, perhaps the key advantage is that ... above all, my work-life balance and everything stemming from it. The key advantage I find in it is that it leaves you with quality time for planning, for thinking clearly about the projects you're doing. I take a day, a day and a half where I feel I'm uninterrupted so you're not leading a life where you're always running around like a headless chicken. (I032_managing partner_part-time teleworking)

The ways and times in which teleworkers do their jobs is usually decided upon by the teleworkers themselves. They organize the relationship between the type of tasks performed and when they are done. It is true that, in many jobs, the work rhythm is not constant and certain times require more dedication than others. Similarly, family demands also vary. In the case of families with children, holiday periods, or when the children are ill, are times when female teleworkers spend less time on their jobs, which they make up for at other times.

\subsubsection{Axis 3: The Effects of Telework}

In the third axis, an assessment of the effects and consequences of teleworking in the context of these life sustainability ecologies was performed. The first consequence identified by our interviewees is an increase in on-the-job performance. This they attribute, basically, to two things. This first is associated with teleworkers' ability to concentrate on their work better and distance themselves from the interruptions generally created in traditional work environments, while the second is directly related to the goal-based organization of work commented on above. Our interviewees note that these goals allow them to work more intensely and efficiently.

I think that those of us who telework, in general, increase our productivity; if they have this debate on the increase in productivity, it's for both the worker and the company. I think it's a very subjective assessment, I think that one of the big problems that we have in knowledge-related jobs is to see what everyone is contributing. I believe that everyone thinks that this goes on a lot and is really productive, but it's difficult to prove and difficult to measure; so, having a good goal-based policy in a company is vital, but it's really not easy. (I032_managing partner_part-time teleworking)

In addition to the above, the interviewees point to the great importance of a perception of control over their lives. This control is closely linked to the freedom they experience when it comes to organizing their time and space. This self-management and self-organization is described as a fluid and harmonious set of options that offers them new stability and life sustainability:

The freedom to choose when to work, and the times that are the deadest, here, or the busiest, you're more productive there, at home, to use it in another ... there are no down times, there are no moments when you say ... "What should I be doing?" Nope. There's always something to do, whether it's for you, for work, for the kids, or for the home. So, [you can] choose how to ensure the best fit between your time and ... work time. The freedom to choose when to work, how to work... (FG9_060_assistant manager_full-time teleworking)

This feeling of control leads to other specific effects associated with their relationship with the organization in which they work. We are referring, firstly, to the loyalty that this form of working 
inspires; these women workers state that they would not change employer even if they were offered a higher salary, as the advantages telework offers them more than offset any others stemming from other forms of compensation or reward. Secondly, there is the resulting engagement. The following quotes make explicit reference to these two effects:

I'm aware that I'm lucky, ok? That ... that ... you can't take this for granted, I mean, that ... the fact is that the more advantages you have, the harder it is for you ... to give up, right? In other words, you suddenly find that ... you assume it's normal, and anything short of these expectations seems horrible. (FG6_045_computer technician_part-time teleworking)

From all of the above, our interviewees can be seen as describing telework as something beyond a mere technical tool which allows them to achieve a better fit between their work and personal lives. It appears as an employment logic or system with a clear political component. Telework is a means of providing life sustainability. Thanks to it, two important facets of their lives can be coordinated, without the need for either one to prevail over the other or to renounce either of them. Additionally, telework is a means of describing the type of organizations in which they work. They are described as wholes (senior management, technological resources, flexible working programs, support, etc.) that foster this sustainability.

Three core factors broadly define what we have dubbed life sustainability ecologies. The first refers to a concern for implementing clear and specific work-life balance-related policies within flexible working programs implemented in a fair and equitable way among all staff. Such programs need to be accompanied by the organization of work based on specific, measurable and quantifiable goals. The second relates to how such policies are greatly appreciated by workers. Furthermore, such measures are seen as a sign of an organization's commitment and the trust it places in its employees. Female teleworkers in organizations of this type view telework as a tool that gives them a boost on the road towards balancing and enjoying the different facets of life (personal, family, professional, etc.). This satisfaction translates to enhanced commitment to the organization to which they belong. Although they are not always physically present there, they are not under the impression that they are renouncing or losing any advantage in their professional careers and believe that they have achieved what they define as a degree of life sustainability that is desirable for all workers. In this regard, these factors show that so-called 'life sustainability' is a key dimension in what we have previously called 'social sustainability'. The third and final factor refers to the fact that sustainability technologies are shaped in organizations in which work and life cultures based on factors such as equality and respect for workers' non-job-related needs are upheld and actively promoted. This factor should be mentioned and borne in mind, as it represents a fundamental difference with what we have named 'presence-based ecologies'.

\subsection{Second Category: Presence-Based Ecologies}

In our research, we found a significant number of women who, although teleworking, did not attest to a life sustainability ecology such as those noted above. Quite the opposite. They stated that their job was carried out in environments in which telework was not appreciated and more importance was attached to a presence-based culture where spending long days at the workplace dominated the work environment. This situation is defined as a 'presence-based ecology', as the logic governing its working hours is based on the value attached to spending many hours at the workplace. The discourse-based axes shaping presence-based ecologies are as follows:

\subsubsection{Axis 1: The Implementation of Telework}

As in the case of life sustainability ecologies, the first axis in this other type of ecology is associated with the implementation of telework in organizations. In this case, technical support for telework is minimal and, in the majority of interviews, it was indicated that it was the teleworker herself who had to bear the costs of this technology. With regard to teleworking programs, the interviewees stated that, 
although there were flextime programs in their organizations that included the option of teleworking, this did not mean that everyone could take advantage of them. Telework was granted by senior management on a discretional basis.

Let's see, the first thing I'd like to say is that I telework, but it's not, it's not in my contract or anything. I mean, it's a benefit I can ... which I can ... , well, I can make work because ... I've got a manager who ... who thinks it's alright. Basically because he's an online manager and he's not Spanish. XXX gives you ... certain benefits, but those who I know working here at a local level, with local bosses, the fact is that they don't, they don't telework, or if they do it's only very sporadically. Because it's not understood. If you're at home, you're not working, and they have to see you at work, you have to be the last to leave, like at any other company here. ( ... ) What's more, I know people it'd suit right down to the ground, and they don't get it. (I011_project manager_full-time teleworking)

Telework can thus appear as part of an organization's policies. Nevertheless, its implementation here is discretional and its criteria, with regard to both implementation and usage, are not communicated transparently. In this regard, our interviewees complained about the lack of support in their organizations. This is due to the fact that the organizational culture is based on physical presence; that is, the time spent at one's desk is highly regarded as a means of assessing performance, engagement and commitment to the organization. In these kinds of dynamics, teleworking is often organized to emulate traditional, presence-based working hours.

... I mean that there are, for example, people who, even though you're teleworking, impose working hours ... in other words, you have to be connected until six in the evening, while there are others who ... for whom it's enough that you're connected for three hours ... . (I037_computer programmer_part-time teleworking)

Interviewees stated that there were great tensions between presence-based working hours and teleworking ones. Female teleworkers in this environment strongly criticized this system and complained that, even though their organizations provided the possibility of teleworking as a measure for achieving a work-life balance, the clash between the realities of telework and the presence-based culture were huge. Unlike in life sustainability ecologies, there is no goal-based organization of work; instead, a worker's engagement and performance is assessed on the amount of time he or she is present at the workplace. Our interviewees expressed their complete disagreement with such dynamics, the effects of which will be examined in the third axis.

\subsubsection{Axis 2: Integration into Domestic and Family Life}

In the case of the second axis in presence-based ecologies, which associates telework with domestic and family life, a painful conflict between the two spheres is made clear:

I think so, in principle at least, but we pay a price, obviously. But, I mean, in theory, yes, I'd agree. Now, to achieve a balance between your work, family and personal lives, it entails ... I dunno ... working from 11 at night to 3 in the morning, because you're connected, and you achieve a balance, yeah, yeah. Thanks to teleworking you achieve this balance, but ... it's that ... I think ... I, at least, feel we pay a price. (FG3_007_lecturer_part-time teleworking)

This conflictive relationship basically finds expression in the excessive workload experienced by these female teleworkers. Our interviewees referred to this situation in terms of exploitation and have asserted that, to a great extent, they themselves are responsible for it. As they arrange their time with a certain degree of freedom, they aspire to 'do it all', be it professionally or in terms of family or household activities, etc. This feeling of excessive workload also leads them to sometimes define telework as a sort of exploitation of oneself by oneself: 
I don't know ... I don't know what, what characteristics we should have ... as ... I already work on the basis that it's ... it's a sort of self-exploitation you're doing, isn't it? (FG2_073_executive assistant_part-time teleworking)

With this kind of dynamic, it is common to hear teleworking referred to as a trap you can fall into. Flexible working hours means that telework makes more time available for the family and the home but the paid work still has to be done, and so family and work commitments end up taking over all their time and creating, on occasion, situations of tiredness, stress and even depression.

But you've also got to qualify this balance a lot ... in other words, of the cases we've raised here, I've at certain times hinted, but I think that no one's understanding telework, be it part-time or not, as I telework, and I give the baby his bottles and clean and go to the bank. Obviously, this is not achieving a work-life balance, this is like ... obviously, it's being superwoman. [ ... ] I work and do 50 other things at the same time, that's no kind of balance... (FG5_020_middle manager_part-time teleworking)

\subsubsection{Axis 3: The Effects of Telework}

In this third axis, an assessment is made of the effects and consequences of teleworking in presence-based ecologies. The first consequence brought up by our interviewees is directly associated with what we have noted with regard to presence-based cultures. These female teleworkers state that, in such contexts, telework means missing out on career opportunities:

Hmm, well, in a way ... it always depends on the company you're in, but, but, it tends to limit your profess ... your promotion. Well, in the case of teleworking, I dunno, because ... only results matter, they don't know how long you've actually been at it, there's no way of knowing, but when you're in a company, what's important is being there. That you're visible. (I001_translator_full-time teleworking)

There is a clear denouncement of the equating of responsibility and commitment with a high degree of physical presence. They make constant criticisms of promotion criteria and policies, as they entail, among other things, becoming involved in pointless logics associated with complete wastes of time, referring to such situations with expressions like brownnosing, lobbying, desk warming, etc. In this regard, there is agreement in asserting that one indispensable precondition for promotion in today's organizations is simply remaining continually physically present.

Because, the way companies do things, why ... do you promote yourself? Well, so that your bosses see that the work you do is good, and how do they see that? With a report you submit to them every six months? They have to see you, they have to ... picture you, that's what I say, OK? (FG5_021_commercial manager_part-time teleworking)

It is interesting to note that many women assume the fact that teleworking may put their career at risk. In the words of one of the interviewees, "they put it on the line" even in those companies in which teleworking is portrayed as an employment option one can freely take advantage of. This situation is expressed by means of the assumption that there will be no chance of promotion, as they are not regarded as true professionals.

Compared with the previous perceptions of organizations offering conditions for what we have dubbed life sustainability, here we clearly see the perception of ecologies in which teleworking is unviable and unsustainable, causing people to experience feelings of guilt and suffering, despite the fact that many of these women argue that telework helps them be more productive and efficient. In addition to all of this, many female teleworkers added that their organizations were still convinced that problems may only be solved through physical presence. This belief means that job dynamics are organized on the basis of one's physical presence, and agreed teleworking times are not respected. Small-scale practices such as the times arranged for face-to-face meetings, working group updates, etc., 
constantly ignore the working hours established for female teleworkers. The following example is highly illustrative of this:

I mean that there are, for example, people who, although you're teleworking, impose specific hours ... in other words, you have to be connected until six in the evening, while there are others who ... for whom it's enough that you're connected for three hours, they may well call you at eight in the evening, and if you're connected, well, you can do something ... an incident ... anything else, and ... well, if you're not connected, well, it doesn't matter. (I037_computer programmer_part-time teleworking)

Unlike in the previous case, in this type of organizational ecology there is no sense of control over one's work-life balance. Teleworking is carried on in a climate of mistrust and penalization. Efforts to achieve a work-life balance tend to cause conflict and stress. In this regard, the majority of interviewees were very clear in expressing the fact that they felt subject to situations of gender inequality. Given that it is women who tend to opt for teleworking, because they directly shoulder the responsibility to achieve this balance, their career progression is interrupted or they are penalized in comparison with their male colleagues.

And, as they don't trust you, I think that often, it's not that ... they require you to work more, but ... they're more demanding, eh, in what you're doing, right? The fact that handing things in there, because you're there ... eh ... it could be that you're there and, and ... you don't finish that day, but as you're there, at the job you're doing, well, heck, at least you've put the hours in. But ... if you don't hand things in perhaps even more quickly ... when you're teleworking, they don't ... don't trust you, they might be thinking, "Honestly, who knows what she's up to?", the same demands in terms of deadlines, or demands, I dunno ... in assignments, right? (FG2_072_journalist_part-time teleworking)

Lastly, it must be added that women who telework in this kind of ecology find it very difficult to escape from the feeling or attitude of always being available or connected in some way. The environment in which they work forces them to be available like this:

It's clear that you're now in a situation in terms of ... of ... technology that gives you the 24/7, the 24/7 that we foster in company, that you have a company that can be ... looking at your products or winning customers or available 24/7, so this means that, nowadays, what you say happens, that you have work $24 / 7$... in other words, you're working 24 hours a day, 7 days a week, right? (FG7_048_middle manager_part-time teleworking)

There is one very clear factor that operates intensely and that defines, ultimately, what presence-based ecologies entail. We are referring here to the time physically spent (or not) at the workplace. In organizations with this type of ecology, teleworking does not constitute an acceptable way of carrying out one's job. It is regarded as a privilege, an eccentricity or a quasi-penalizing regime used by those not fully committed to their job. Furthermore, our female teleworkers stated that presence-based cultures reject or shun family or private life, as it is considered completely secondary to work, the only environment in which one can achieve full personal realization. It is precisely in this point that there is a denouncement of organizations with this type of culture as unsustainable undertakings. For our women interviewees, it is obvious that a culture that does not foster life outside of work, a work-life balance or personal satisfaction beyond one's job is a culture that, due to its inhumanity, is neither sustainable nor has any future.

A summary of our results are listed in Table 3 below: 
Table 3. Summary of the main results of the analysis.

\begin{tabular}{|c|c|c|c|c|}
\hline & $\begin{array}{c}\text { 1. The Implementation } \\
\text { of Telework }\end{array}$ & $\begin{array}{l}\text { 2. Integration into } \\
\text { Domestic and } \\
\text { Family Life }\end{array}$ & $\begin{array}{l}\text { 3. The Effects of } \\
\text { Telework }\end{array}$ & General Results \\
\hline $\begin{array}{l}\text { Life Sustainability } \\
\text { Ecologies }\end{array}$ & $\begin{array}{l}\text {-Organizations offer } \\
\text { adequate technological } \\
\text { support for teleworking } \\
\text {-Organizations offer } \\
\text { explicit work-life } \\
\text { balance programs } \\
\text {-Senior managers and } \\
\text { non-teleworking staff } \\
\text { openly express } \\
\text { their support }\end{array}$ & $\begin{array}{l}\text {-Time is } \\
\text { self-managed } \\
\text {-Autonomy } \\
\text {-Independence } \\
\text {-Strong sense of } \\
\text { control over } \\
\text { one's life }\end{array}$ & $\begin{array}{l}\text {-Better job } \\
\text { performance } \\
\text {-Perception of control } \\
\text { over one's life } \\
\text {-Harmonious } \\
\text { self-management } \\
\text {-More loyalty and } \\
\text { engagement with } \\
\text { the organization }\end{array}$ & $\begin{array}{l}\text {-All staff can telework } \\
\text {-Physical absence is not } \\
\text { penalized } \\
\text {-Teleworkers do not } \\
\text { feel that their } \\
\text { professional career } \\
\text { is threatened }\end{array}$ \\
\hline $\begin{array}{l}\text { Presence-Based } \\
\text { Ecologies }\end{array}$ & $\begin{array}{l}\text {-Minimal technical } \\
\text { support for teleworking } \\
\text {-Teleworking is } \\
\text { considered a perkfor } \\
\text { senior managers } \\
\text {-Tensions exist between } \\
\text { presence-based working } \\
\text { hours and } \\
\text { teleworking ones }\end{array}$ & $\begin{array}{l}\text {-Teleworking is } \\
\text { considered a trap } \\
\text { as it translates to } \\
\text { more working } \\
\text { hours }\end{array}$ & $\begin{array}{l}\text {-Teleworking entails } \\
\text { missing out on career } \\
\text { opportunities } \\
\text {-Responsibility and } \\
\text { commitment are } \\
\text { equated to a high } \\
\text { degree of physical } \\
\text { presence } \\
\text {-No control over one's } \\
\text { work-life balance } \\
\text {-Teleworkers end up } \\
\text { being available to the } \\
\text { organization } 24 / 7\end{array}$ & $\begin{array}{l}\text {-Use of telework is } \\
\text { discretional } \\
\text {-Teleworking is a perk } \\
\text { reserved for senior } \\
\text { managers } \\
\text {-The issue of work-life } \\
\text { balance is not } \\
\text { considered relevant } \\
\text {-Presence-based } \\
\text { working is seen as the } \\
\text { rule governing an } \\
\text { organization's } \\
\text { entire behavior }\end{array}$ \\
\hline
\end{tabular}

\section{Discussion: Organizations, Work-Life Balance and Social Sustainability}

There is an interesting factor that we have not yet mentioned and that appears to influence the shaping and defining of life sustainability or presence-based ecologies. This is the size and the sector of the organization in which our interviewees work. Sustainability ecologies appear in the discourse of those working in large companies, while a presence-based ecology does so in those working for small and medium-sized enterprises. Similarly, the former tends to appear in organizations in the communications sector, while the latter does so in other types of organizations. Lastly, mention should be made of the fact that the former type of ecology is defined by those working in organizations with clear corporate social responsibility policies, while the latter appears in companies in which this issue is not regarded as important.

Given all of the above, we see that the impact that teleworking may have on one's everyday life depends upon the following factors: (a) the support offered by an organization, from both senior managers and non-teleworking staff members; (b) the degree of autonomy permitted when it comes to organizing one's own time and space, as well as the tasks to be performed; and (c) the degree of penalization associated (or not) with this new form of working by the organization. The so-called life sustainability ecologies allow all staff to telework, do not penalize one's physical absence from the workplace, and women workers do not experience any threats to their professional careers. On the other hand, in presence-based ecologies, the use of telework as a form of employment is discretional; it is not based on clear criteria, is considered a perk, is at the mercy of decisions made by senior management and is not associated with achieving a work-life balance. Furthermore, presence-based working is seen as the rule governing organizations' entire behavior.

Compared with such a presence-based mentality, life sustainability ecologies prescribe flexibility as a solution. Work is planned on a goal-based approach, assessments are not made on the basis of time physically spent at the workplace and results are evaluated in terms of quality. This type of ecology tends to set more realistic goals in terms of fulfilment and takes into account workers' personal and family situations. Efforts are made not to organize meetings after school hours, during the school holidays or at weekends. This is not the case in presence-based ecologies, which require workers to be available 24/7. Additionally, we can state that life sustainability ecologies show a greater respect for equality of rights between genders and reject any kind of discrimination. The careers of their women 
workers are as respected and safeguarded as those of their male colleagues. In this regard, it is no exaggeration to state that organizations with a life sustainability ecology are fully compliant with the goals sought by social sustainability. By way of contrast, presence-based ecologies are associated with organizations that are standing in the way of their fulfilment.

\section{Conclusions}

The word telework may appear to denote a homogenous reality, usually characterized by two dimensions. On the one hand, it is seen as a technology-based way of working. On the other, it has an organizational connotation that often relates to issues surrounding the way in which work is managed through this form of employment. Nevertheless, as shown in Table 3, this reality is, in fact, heterogeneous, hiding differences and a range of problems brought on by political, cultural, ethical and very much everyday issues. It is clear that teleworking entails an increase in flexibility for its users-something clearly posed by a lot of our interviewees. It can also prove to be a useful tool for achieving a work-life balance. However, this form of work invokes widely varying experiences. Successes, failures and misunderstandings in its usage are intermeshed with cultural issues in organizations that foster or hinder such experiences. This proves evident when comparing the two columns of Table 3. Ultimately, organizations attempting to use telework as a measure for achieving a work-life balance while also retaining a strong presence-based culture are setting themselves up for failure.

The two ecologies detected in our research-life sustainability ecologies and presence-based ecologies-highlight the fact that telework is much more than a new way of working. The opinions of the female teleworkers in our study show us that it is also used as a political tool and as an instrument for denouncing certain organizational practices. Similarly, our study participants commented on how the success of telework as a measure for achieving a work-life balance establishes productive harmony between the individual, the organization and the community. Therefore, telework has proved itself to be a key component of organizational realities that are aligned with social sustainability agendas. Although it can help workers achieve this work-life balance, telework on its own is no guarantee of success in this regard, nor as a tool that per se fosters such sustainability. It needs to be surrounded by a context of support and promotion, which is directly related to organizational cultures. Changing these cultures to foster this form of working and the general sustainability that its employment can entail is undoubtedly one of the great challenges facing the knowledge-based economy.

Author Contributions: Conceptualization: A.G., F.T., M.J.M.; Data curation: A.G., F.T.; Formal Analysis: A.G., F.T.; Methodology: A.G., F.T.; Writing-original draft: A.G., F.T., M.J.M.; Writing-review editing: A.G., F.T. All authors have read and agreed to the published version of the manuscript.

Funding: This research received no external funding.

Conflicts of Interest: The authors declare no conflict of interest.

\section{References}

1. United Nations. 17 Goals to Transform Our World. Available online: http://www.un.org/ sustainabledevelopment (accessed on 1 April 2019).

2. George, G.; Howard-Grenville, J.; Joshi, A.; Tihanyi, L. Understanding and tackling societal grand challenges through management research. Acad. Manag. J. 2016, 59, 1880-1895. [CrossRef]

3. Warren, M.; Donaldson, S.; Lee, J.; Donaldson, S. Reinvigorating Research on Gender in the Workplace Using a Positive Work and Organizations Perspective. Int. J. Manag. Rev. 2019, 21, 498-518. [CrossRef]

4. Savaneviciene, A.; Stankeviciute, Z. Smart Power as a Pathway for Employing Sustainable Human Resource Management. Eng. Econ. 2017, 28, 198-206. [CrossRef]

5. Delmas, M.A.; Lyon, T.P.; Maxwell, J.W. Understanding the role of the corporation in sustainability transitions. Organ. Environ. 2019, 32, 87-97. [CrossRef] 
6. Vogel, D. Promoting Sustainable Government Regulation: What We Can Learn from California. Org. Environ. 2019, 32, 145-158. [CrossRef]

7. Crifo, P.; Durand, R.; Gont, J.P. Encouraging Investors to Enable Corporate Sustainability Transitions: The Case of Responsible Investment in France. Organ. Environ. 2019, 32, 125-144. [CrossRef]

8. De Stefano, F.; Bagdadli, S.; Camuffo, A. The HR role in corporate social responsibility and sustainability: A boundary-shifting literature review. Hum. Resour. Manag. 2017, 57, 549-566. [CrossRef]

9. Di Fabio, A. The Psychology of Sustainability and Sustainable Development for Well-Being in Organizations. Front. Psychol. 2017, 8, 1534. [CrossRef]

10. Baumgartner, R.; Rauter, R. Strategic perspectives of corporate sustainability management to develop a sustainable organization. J. Clean. Prod. 2016, 140, 81-92. [CrossRef]

11. Sorensen, S. The performativity of choice: Postfeminist perspective on work-life balance. Gen. Work Organ. 2017, 24, 297-313. [CrossRef]

12. Freeney, M.K.; Stritch, J.M. Family-friendly policies, gender, and work-life balance in public sector. Rev. Public Pers. Adm. 2019, 39, 422-448. [CrossRef]

13. Lewis, S.; Beauregard, T. The meanings of work-life balance: A cultural perspective. In The Cambridge Handbook of the Global Work-Family Interface; Johnson, R., Shen, W., Shockley, K.M., Eds.; Cambridge University Press: Cambridge, UK, 2018; pp. 720-732.

14. Emslie, C.; Hunt, K. Live to work or work to live? A qualitative study of gender and work-life balance among men and women in mid-life. Gen. Work Organ. 2009, 16, 151-172. [CrossRef]

15. Gregory, A.; Milner, S. Work-life balance: A matter of choice? Gen. Work Organ. 2009, 16, 1-13. [CrossRef]

16. Halrynjo, S. Men's work-life conflict: Career, care and self-realization: Patterns of privileges and dilemmas. Gen. Work Organ. 2009, 16, 98-125. [CrossRef]

17. Maume, D.; Sebastian, R.; Bardo, A. Gender, work-family responsibilities, and sleep. Gen. Soc. 2010, 24, 746-768. [CrossRef]

18. Watts, J.H. Allowed into a man's world meanings of work-life balance: Perspectives of women civil engineers as "minority" workers in construction. Gen. Work Organ. 2009, 16, 37-57. [CrossRef]

19. Adisa, T.; Abdulraheem, I.; Isiaka, S. Patriarchal hegemony: Investigating the impact of patriarchy on women's work-life balance. Gen. Manag. 2019, 34, 19-33. [CrossRef]

20. De Klerk, M.; Mostert, K. Work-home interference: Examining socio-demographic predictors in the South African context. J. Hum. Resour. Manag. 2010, 8, 10. [CrossRef]

21. Hsiao-Ping, C.; Chi-Ming, H.; Meei-Ying, L.; Han-Shen, C. Examining the Moderating Effects of Work-Life Balance between Human Resource Practices and Intention to Stay. Sustainability 2019, 11, 4585.

22. Klindzic, M.; Maric, M. Flexible work arrangements and organizational performance -the difference between employee and employer-driven practices. J. Gen. Soc. Issues 2019, 28, 89-108.

23. Rao, I. Work-Life Balance for Sustainable Human Development: Cultural Intelligence as Enabler. J. Hum. Behav. Soc. Environ. 2017, 7, 706-713. [CrossRef]

24. Alina-Mihaela, D.; Tuclea, C.E.; Vrânceanu, D.M.; Tigu, G. Sustainable Social and Individual Implications of Telework: A New Insight into the Romanian Labor Market. Sustainability 2019, 11, 3506.

25. Malenfant, R. Risk, Control and Gender: Reconciling Production and Reproduction in the Risk Society. Organ. Stud. 2009, 30, 205-226. [CrossRef]

26. Tietze, S.; Musson, G. Identity, identity work and the experience of working from home. J. Manag. Dev. 2010, 29, 148-156. [CrossRef]

27. Lister, K.; Harnish, T. Workshifting Benefits: The Bottom Line. 2010. Available online: http://www. workshifting.com/downloads/downloads/Workshifting\%20Benefits-The\%20Bottom\%20Line.pdf (accessed on 1 September 2014).

28. Mirchandani, K. The best of both worlds and Cutting my own throat: Contradictory images of home-based work. Qual. Sociol. 2000, 23, 159-182. [CrossRef]

29. Gregg, M. Work's Intimacy; Polity Press: Cambridge, UK, 2011.

30. Kanellopoulos, D. How Can Teleworking Be Pro-Poor? J. Enterp. Inf. Manag. 2011, 24, 8-29. [CrossRef]

31. Daniels, K.; Lamond, D.; Standen, P. Teleworking: Frameworks for organizational research. J. Manag. 2001, 38, 1151-1185. [CrossRef] 
32. Pyöriä, P. Managing Telework: Risks, Fears and Rules. Manag. Res. Rev. 2011, 34, 386-399. [CrossRef]

33. Sarker, S.; Xiao, X.; Sarker, S.; Ahuja, M. Managing employees' use of mobile technologies to minimize work-life balance impacts. MIS Q. Exec. 2012, 11, 143-157.

34. Vega, R.; Anderson, A.; Kaplan, S. A within-Person Examination of the Effects of Telework. J. Bus. Psychol. 2015, 30, 313-323. [CrossRef]

35. Wheatley, D. Good to Be Home? Time-Use and Satisfaction Levels among Home-Based Teleworkers'. New Technol. Work Employ. 2012, 27, 224-241. [CrossRef]

36. Hilbrecht, M.; Shaw, S.; Johnson, L.; Andrey, J. Remixing work, family and leisure: Teleworkers' experiences of everyday life. New Technol. Work Employ. 2013, 28, 130-144. [CrossRef]

37. Lewis, S. Restructuring workplace cultures: The ultimate work-family challenge? Women Manag. Rev. 2001, 16, 21-29. [CrossRef]

38. Tremblay, D. Work-Family Balance: What Are the Sources of Difficulty and What Could Be Done? Research Note, $\mathrm{n}^{\circ}$ 2004-03A of Canada Research Chair on the Socio-Organizational Challenges of the Knowledge Economy; Université du Québec: Quebec, QC, Canada, 2004.

39. Gurstein, P. Wired to the World, Chained to the Home: Telework in Daily Life; University of British Columbia Press: Vancouver, BC, Canada, 2001.

40. King, E.B.; Botsford, W.E.; Huffman, A.H. Work, Family, and Organizational Advancement: Does Balance Support the Perceived Advancement of Mothers? Sex Roles 2009, 61, 879-891. [CrossRef]

41. Wilson, M.; Greenhill, A. Gender and teleworking identities in the risk society: A research agenda. New Technol. Work Employ. 2004, 19, 207-221. [CrossRef]

42. Brannen, J. Time and the Negotiation of Work-Family Boundaries: Autonomy or illusion? Time Soc. 2005, 14, 113-131. [CrossRef]

43. Fonner, K.; Stache, L. All in a day's work, at home: Teleworkers' management of micro role transitions and the work-home boundary. New Technol. Work Employ. 2012, 27, 242-257. [CrossRef]

44. Nätti, J.; Tammelin, M.; Anttila, T.; Ojala, S. Work at home and time use in Finland. New Technol. Work Employ. 2011, 26, 68-77. [CrossRef]

45. Halford, S. Hybrid workspace: Re-spatialisations of work, organisation and management. New Technol. Work Employ. 2005, 20, 19-33. [CrossRef]

46. Ibrahim, Y. Temporality, space and technology: Time-space discourses of call centres. New Technol. Work Employ. 2012, 27, 23-35. [CrossRef]

47. Fogary, H.; Scott, P.; Willians, S. The half-empty office: Dilemmas in managing locational flexibility. New Technol. Work Employ. 2011, 26, 183-195. [CrossRef]

48. Jaakson, K.; Kallaste, E. Beyond flexibility: Reallocation of responsibilities in the case of telework. New Technol. Work Employ. 2010, 25, 196-209. [CrossRef]

49. Gold, M.; Mustafa, M. 'Work always wins': Client colonisation, time management and the anxieties of connected freelancers. New Technol. Work Employ. 2013, 28, 197-211. [CrossRef]

50. Block, A.; Farias, I. Urban Cosmopolitics: Agencements, Assemblies, Atmospheres (Questioning Cities); Routledge: London, UK, 2016.

51. Farias, I.; Benders, T. Urban Assemblages: How Actor-Network Theory Changes Urban Studies (Questioning Cities); Routledge: London, UK, 2010.

52. White, P.; Christodoulou, G.; Mackett, R.; Titheridge, H.; Thoreau, R.; Polak, J. The impacts of Teleworking on Sustainability and Travel. In Social Sustainaibility in Urban Areas: Communities, Connectivity and Social Fabric; Manzi, T., Lucas, K., Lloyd-Jones, T., Allen, J., Eds.; Earthscan: London, UK, 2010; pp. 141-160.

53. Burnett, S.B.; Gatrell, C.J.; Cooper, C.L.; Sparrow, P. Well-balanced families? A gendered analysis of work-life balance policies and work family practices. Gen. Manag. 2010, 25, 534-549.

54. Dilmaghani, M.; Tabvuma, V. The gender gap in work-life balance satisfaction across occupations. Gen. Manag. 2019, 34, 398-428. [CrossRef]

55. Tang, N.; Cousins, C. Working time, gender and family: An East-West European comparison. Gen. Work Organ. 2005, 12, 527-550. [CrossRef]

56. Strazdins, L.; Broom, D. Acts of love (and work) gender imbalance in emotional work and women's psychological distress. J. Fam. Issues 2004, 25, 356-378. [CrossRef] 
57. Beham, B.; Präg, P.; Drobnic, S. Who's got the balance? A study of satisfaction with the work-family balance among part-time service sector employees in five Western European countries. Int. J. Hum. Resour. Man. 2012, 23, 3725-3741. [CrossRef]

58. Coltrane, S. Gender theory and household labor. Sex Roles 2010, 63, 791-800. [CrossRef]

59. Gerson, K. Dilemmas of involved fatherhood. In Gender and Work in Today's World; Sacks, N., Marrone, C., Eds.; Westview Press: Cambridge, UK, 2004; pp. 378-386.

60. Chung, H.; Van der Horst, M. Women's employment patterns after childbirth and the perceived access to and use of flexitime and teleworking. Hum. Relat. 2017, 71, 47-72. [CrossRef]

61. Sullivan, C.; Lewis, S. Home-based telework, gender and the synchronization of work and family: Perspectives of teleworkers and their co-residents. Gen. Work Organ. 2001, 8, 123-145. [CrossRef]

62. Haar, J.; Carr, S.; Arrowsmith, J.; Parker, J.; Hodgetts, D.; Alefaio-Tugia, S. Escape from Working Poverty: Steps toward Sustainable Livelihood. Sustainability 2018, 10, 4144. [CrossRef]

63. World Commission on Environment and Development. Our Common Future; University Press: Oxford, UK, 1987.

64. Chandra, V. Work-life balance: Eastern and western perspectives. Int. J. Hum. Resour. Man. 2012, 23, 100-113. [CrossRef]

65. White, E.; Thatcher, A. How Mobile Phones Affect the Sustainability of the Work/Life Balance of Their Users. In International Conference on Augmented Cognition; Springer: Cham, Switzerland, 2015; pp. 393-400.

66. Mushfiqur, R.; Mordi, C.; Oruh, E.; Nwagbara, U.; Mordi, T.; Turner, I. The impacts of work-life-balance (WLB) challenges on social sustainability: The experience of Nigerian female medical doctors. Empl. Relat. 2019, 40, 868-888. [CrossRef]

67. Kobayashi, K.; Eweje, G.; Tappin, D. Employee wellbeing and human sustainability: Perspectives of managers in large Japanese corporations. Bus. Strateg. Environ. 2018, 27, 801-810. [CrossRef]

68. Fleetwood, S. Why work-life balance now? J. Hum. Resour. 2007, 18, 351-375. [CrossRef]

69. Gambles, R.; Lewis, S.; Rapoport, R. The Myth of Work-Life Balance: The Challenges of Our Time for Men, Women and Societies; Wiley: Chichester, UK, 2006.

70. Houston, D.M. Work-Life Balance in the 21st Century; Palgrave Macmillan: Basingstoke, UK, 2005.

71. Foucreault, A.; Ollier-Malaterre, A.; Julie Ménard, J. Organizational culture and work-life integration: A barrier to employees' respite? J. Hum. Resour. 2018, 29, 2378-2398. [CrossRef]

72. Crompton, R.; Lyonette, C. Occupational class, country and the domestic division of labour. In Women, Men, Work and Family in Europe; Crompton, R., Lewis, S., Lyonette, C., Eds.; Palgrave: London, UK, 2007; pp. 116-132.

73. Duncan, S. Mothers' work-life balance: Individualized preferences or cultural construction? In Gender Divisions and Working Time in the New Economy: Changing Patterns of Work, Care and Public Policy in Europe and North America; Perrons, D., Fagan, C., McDowell, L., Ray, K., Ward, K., Eds.; Edward Elgar: Cheltenham, UK, 2007; pp. 127-147.

74. Singley, S.; Hynes, K. Transitions to parenthood: Work-family policies, gender and the couple context. Gen. Soc. 2005, 19, 376-397. [CrossRef]

75. Adame, C.; Eva-María Caplliure, E.M.; María-José Miquel, M.J. Work-life balance and firms: A matter of women? J. Bus. Res. 2016, 69, 1379-1383. [CrossRef]

76. Russo, M.; Shteigman, A.; Carmeli, A. Workplace and family support and work-life balance: Implications for individual psychological availability and energy at work. J. Posit. Psychol. 2016, 11, 173-188. [CrossRef]

77. Thompson, C.A.; Prottas, D. Relationships among organizational family support, job autonomy, perceived control, and employee well-being. J. Occup. Health Psychol. 2005, 10, 100-118. [CrossRef] [PubMed]

78. Cooper, M. Being the "go-to-guy": Fatherhood, masculinity and the organization of work in Silicon Valley. Qual. Sociol. 2000, 23, 379-405. [CrossRef]

79. Rapoport, R.; Bailyn, L.; Fletcher, J.K.; Pruitt, B.H. Beyond Work-Family Balance; Jossey-Bass: San Francisco, CA, USA, 2002.

80. McDonald, P.; Brown, K.; Bradley, L. Explanations for the provision-utilisation gap in work-life policy. Women Manag. Rev. 2005, 20, 7-55. [CrossRef]

81. Haar, J.; Russo, M.; Suñe, A.; Ollier-Malaterre, A. Outcomes of work-life balance on job satisfaction, life satisfaction and mental health: A study across seven cultures. J. Voc. Behav. 2014, 85, 361-373. [CrossRef] 
82. Siu, O.; Lu, J.; Brough, P.; Lu, C.; Bakker, A.; Kalliath, T.; O’Driscoll, M.; Phillips, D.; Chen, W.; Lo, D.; et al. Role resources and work-family enrichment: The role of work engagement. J. Voc. Behav. 2010, 77, 470-480. [CrossRef]

83. Roscoe, S.; Subramanian, N.; Jabbour, C.; Chong, T. Green human resource management and the enablers of green organisational culture: Enhancing a firm's environmental performance for sustainable development. Bus. Strategy Environ. 2019, 28, 737-749. [CrossRef]

84. Jaramillo, J.; Sossa, J.; Mendoza, G. Barriers to sustainability for small and medium enterprises in the framework of sustainable development-Literature review. Bus. Strategy Environ. 2018, 28, 512-524.

85. Díaz, A.; Sainz, J.; Torrent, J. The competitiveness of small network-firm: A practical tool. J. Bus. Res. 2016, 69, 1769-1774. [CrossRef]

86. Díaz, A.; Ficapal, P.; Torrent, J. Did small and medium enterprises maintain better jobs during the early years of the recession? Job quality multidimensional evidence from Spain. Eur. Manag. J. 2017, 35, 396-413. [CrossRef]

87. Barber, L.K.; Grawitch, M.J.; Maloney, P.W. Work-life balance: Contemporary perspectives. In The Psychologically Healthy Workplace: Building a Win-Win Environment for Organizations and Employees; Grawitch, M.J., Ballard, D.W., Eds.; American Psychological Association: Washington, DC, USA, 2016; pp. 111-133.

88. Angell, I. The New Barbarian Manifesto: How to Survive the Information Age; Kogan Page: London, UK, 2000.

89. Bailey, D.E.; Kurland, N.B. A review of telework research: Findings, new directions, and lessons for the study of modern work. J. Organ. Behav. 2002, 23, 383-400. [CrossRef]

90. Handy, C. The Age of Unreason; Arrow Books: London, UK, 1990.

91. Kowalski, K.B.; Swanson, J.A. Critical success factors in developing teleworking programs. Benchmark. Int. J. 2005, 12, 236-249. [CrossRef]

92. Baruch, Y. The status of research on teleworking and an agenda for future research. Int. J. Manag. Rev. 2001, 3, 113-120. [CrossRef]

93. Loubier, A. Benefits of Telecommuting for the Future of Work. 2017. Available online: https://www.forbes.com/ sites/andrealoubier/2017/07/20/benefits-of-telecommuting-for-the-future-of-work/\#7e6db2c116c6 (accessed on 20 November 2019).

94. Pinola, M. Differences between Telecommuting and Telework. 2018. Available online: https://www.lifewire. com/difference-between-telecommuting-and-telework-2378090 (accessed on 15 November 2019).

95. Karia, N.; Muhammad, A. Innovation Capability: The Impact of Teleworking on Sustainable Competitive Advantage. Int. J. Technol. Pol. Manag. 2016, 16, 181-194. [CrossRef]

96. Kazekami, S. Mechanisms to improve labor productivity by performing telework. Telecom. Policy 2020, 44, 101868. [CrossRef]

97. Moon, C.; Stanworth, C. Ethical issues of teleworking. Bus. Ethics 1997, 6, 30-34. [CrossRef]

98. Sennett, R. The Corrosion of Character; Norton \& Company: New York, NY, USA, 1998.

99. Aguilera, A.; Lethiais, V.; Rallet, A.; Proulhac, L. Home-based telework in France: Characteristics, barriers and perspectives. Transp. Res. Part A Policy Pract. 2016, 92, 1-11. [CrossRef]

100. Lee, S.-H.; Shin, Y.; Baek, S.I. Task Characteristics and Work Engagement: Exploring Effects of Role Ambiguity and ICT Presenteeism. Sustainability 2017, 9, 1855.

101. Yoo, W.; Oh, I. Effect of Work-Family Balance Policy on Job Selection and Social Sustainability: The Case of South Korea. Sustainability 2017, 9, 849. [CrossRef]

102. Hynes, M.; Rau, H. Environmental Gains and Social Losses? Critical reflections on the sustainability potential of telework. In Proceedings of the XVIII ISA World Congress of Sociology, Yokohama, Japan, 13-19 July 2014.

103. Felstead, A.; Jewson, N. In Work at Home. Towards and Understanding of Homeworking; Routledge: London, UK, 2000.

104. Tietze, S.; Musson, G. When Work Meets Home: Temporal flexibility as lived experience. Time Soc. 2002, 11, 315-334. [CrossRef]

105. Patton, M. Qualitative Research and Evaluation Methods; Sage: Thousand Oaks, CA, USA, 2002.

106. Lawrence, H. Ecology. Encyclopedia of Science; Salem Press: New York, NY, USA, 2013. 
107. Green, L.; Richard, L.; Potvin, L. Ecological foundations of health promotion. Am. J. Health Promot. 1996, 10, 270-281. [CrossRef]

108. Lorway, R.; Lazarus, L.; Chevrier, C.; Khan, S.; Musyoki, H.; Mathenge, J.; Mwangi, P.; Macharia, P.; Bhattacharjee, P.; Isac, S.; et al. Ecologies of security: On the everyday security tactics of female sex workers in Nairobi, Kenya. Glob. Public Health 2018, 13, 1767-1780. [CrossRef] [PubMed]

(C) 2020 by the authors. Licensee MDPI, Basel, Switzerland. This article is an open access article distributed under the terms and conditions of the Creative Commons Attribution (CC BY) license (http://creativecommons.org/licenses/by/4.0/). 